\title{
Chromosome numbers of populations of three varieties of Bidens pilosa in Taiwan
}

Ya-Lun Huang ${ }^{1}$ and Wen-Yuan Kao ${ }^{1,2^{*}}$

\begin{abstract}
Background: Hairy beggar-ticks (Bidens pilosa L.) is a common invasive plant in tropical and subtropical regions. The Flora of Taiwan listed three varieties of B. pilosa in Taiwan, var. minor, var. pilosa and var. radiata. Among the three varieties, var. radiata was the most recently, in 1970s, introduced into Taiwan. However, after its introduction into Taiwan, var. radiata has become dominant over the other two varieties and is considered a serious invasive plant in lowland of Taiwan. Our previous study showed that var. radiata is self-incompatible and the other two varieties are self-fertile. Could it be possible that different chromosome numbers contribute to the different breeding systems of these three varieties? In addition, the heterogeneities of traits of var. radiata were found higher than those of var. minor and var. pilosa. Is the phenomenon resulting from the hybridization between var. radiata with other varieties? We counted chromosome numbers of populations of these three varieties distributed in Taiwan and conducted hand pollination treatment between var. radiata (as pollen receiver) and var. minor or var. pilosa (as pollen donor) to provide answer for the aforementioned questions.

Results: No difference was found in chromosome numbers among populations of the same variety. Forty-eight chromosomes $(2 n=48)$ were counted for var. radiata while $72(2 n=72)$ chromosomes for var. minor and var. pilosa. Therefore, var. radiata is tetraploid and var. minor and var. pilosa are hexaploid. No successful hybridization was found between var. radiata and var. minor or between var. radiata and var. pilosa.
\end{abstract}

Conclusions: This study provided the evidence that the invasive plant (B. pilosa var. radiata) has different chromosome numbers from the other two varieties and is unlikely to hybridize with the other two varieties.

Keywords: Bidens pilosa, Chromosome number, Crossing, Invasive plant, Self-incompatibility

\section{Background}

Bidens pilosa L. (Hairy beggar-ticks, Asteraceae) is a cosmopolitan weed. With its diversification center in Mexico, it is widely distributed in tropical and subtropical regions (Ballard 1986). This taxon is an annual or perennial herb with square stems and opposite leaves and often occupies roadsides, disturbed sites and cultivated fields (Peng et al. 1998). Based on the morphological differences, B. pilosa was classified into six varieties: var. pilosa, var. minor, var. radiata, var. bimucronata, var. calcicola, and var. alausensis (Sherff 1937). Accordingly, The Flora of Taiwan listed three varieties of B. pilosa L. in

\footnotetext{
*Correspondence: wykao@ntu.edu.tw

${ }^{1}$ Institute of Ecology and Evolutionary Biology, National Taiwan

University, 1, Roosevelt Rd., Sec. 4, Taipei 106, Taiwan

Full list of author information is available at the end of the article
}

Taiwan, i.e. var. minor, var. pilosa and var. radiata (Peng et al. 1998). The most obvious differences in morphology among these three varieties are their flowers (Fig. 1). The capitula of var. pilosa are discoid (without ray florets), and the capitula of var. minor and var. radiata are radiate (with ray florets). Although var. minor and var. radiata both have ray florets, their ray florets are quite different. B. pilosa var. minor have eight ray florets which are often shorter than $8 \mathrm{~mm}$ while var. radiata have 5-8 ray florets which are often longer than $10 \mathrm{~mm}$. Thirty years ago, var. minor was widely distributed in Taiwan. However, after var. radiata being introduced into Taiwan, var. radiata has become a serious invasive plant and dominant over the other two varieties within 30 years (Wu et al. 2004, 2010).

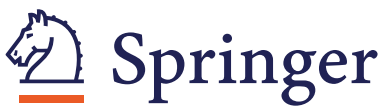

(c) 2015 Huang and Kao. This article is distributed under the terms of the Creative Commons Attribution 4.0 International License (http://creativecommons.org/licenses/by/4.0/), which permits unrestricted use, distribution, and reproduction in any medium, provided you give appropriate credit to the original author(s) and the source, provide a link to the Creative Commons license, and indicate if changes were made. 

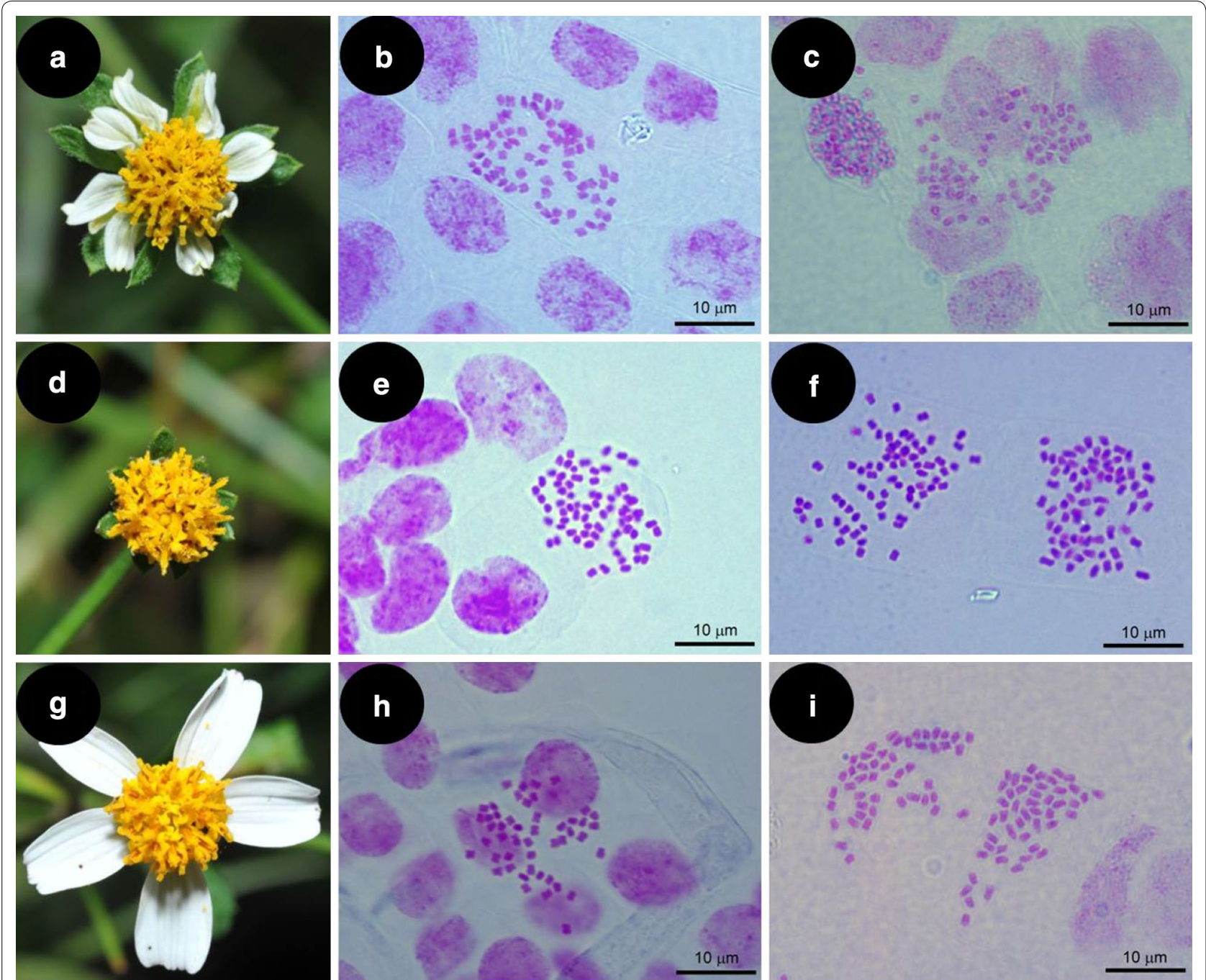

Fig. 1 Pictures of inflorescence and somatic chromosomes of three varieties of Bidens pilosa in Taiwan. Representatives of inflorescence of var. minor $(\mathbf{a})$, var. pilosa $(\mathbf{d})$ and var. radiata $(\mathbf{g})$ and somatic chromosomes of roots sampled from two different populations of each variety: var. minor from Chiayi $(2 n=72)(\mathbf{b})$ and from Yilan $(2 n=72)(\mathbf{c})$, var. pilosa from Hualien $(2 n=72)(\mathbf{e})$ and from Chiayi $(2 n=72)(\mathbf{f})$ and var. radiata from Nantou $(2 n=48)(\mathbf{h})$ and from Yilan $(2 n=48)(\mathbf{i})$ county in Taiwan

A previous study on breeding systems of these three varieties demonstrated that var. minor and var. pilosa are self-compatible while var. radiata is self-incompatible (Huang and Kao 2014). Chromosome numbers and breeding systems of 200 populations of B. pilosa in southern United States, Mexico and Central America have been investigated to clarify the classification of $B$. pilosa (Ballard 1986). After the analyses, Ballard concluded that B. pilosa in North and Central America should be treated as a species complex containing three species with different chromosome numbers due to different ploidy: $B$. odorata $(2 n=24)$, B. alba $(2 n=48)$ and B. pilosa $(2 n=72)$. Species with different polyploidy also had different breeding system: hexaploid populations were self-fertile while diploid and tetraploid populations were self-incompatible. According to Ballard's result, could it be possible that the chromosome number of var. radiata is different from that of var. minor and var. pilosa?

Furthermore, many traits of var. radiata were found having higher variation than those of var. minor and var. pilosa. For example, highly variation in ray floret numbers and sizes was found in var. radiata, while all var. minor had eight ray florets with similar size in each capitulum. Significant variations in pollen/ovule ratio and disc floret numbers per capitulum were only found in var. radiata but not in var. minor and var. pilosa (Huang and Kao 2014). Because var. radiata is self-incompatible and sometimes growing sympatrically with var. minor 
and var. pilosa, could it be possible that the var. radiata can hybridize with the other two varieties resulting in the highly variation in these traits?

The objectives of this study were to understand (1) whether these three varieties have different chromosome numbers, and (2) whether B. pilosa var. radiata can hybridize with var. minor or var. pilosa. To achieve the goal, we counted chromosome numbers of populations of these three varieties in Taiwan and conducted hand pollination treatments between var. radiata (as pollen receiver) and var. minor or var. pilosa (as pollen donors).

\section{Methods}

\section{Chromosome count}

Achenes of three varieties of $B$. pilos $a$ were collected from 5-8 populations distributed in Taiwan (Fig. 2). The collected achenes were planted in $1 \mathrm{~L}$ pots for about 1 month. When plants reached $20 \mathrm{~cm}$ height with 4-5 paired leaves, their shoots were cut and immersed into water for growing adventitious roots (Hsu and Kao 2014).

When shoots growing adventitious roots of 3-5 cm, the emergent rootlets with root-tips $(\mathrm{ca} .1-2 \mathrm{~cm})$ were cut, pretreated with $2 \mathrm{mM}$ 8-hydroxyquinoline at $14{ }^{\circ} \mathrm{C}$

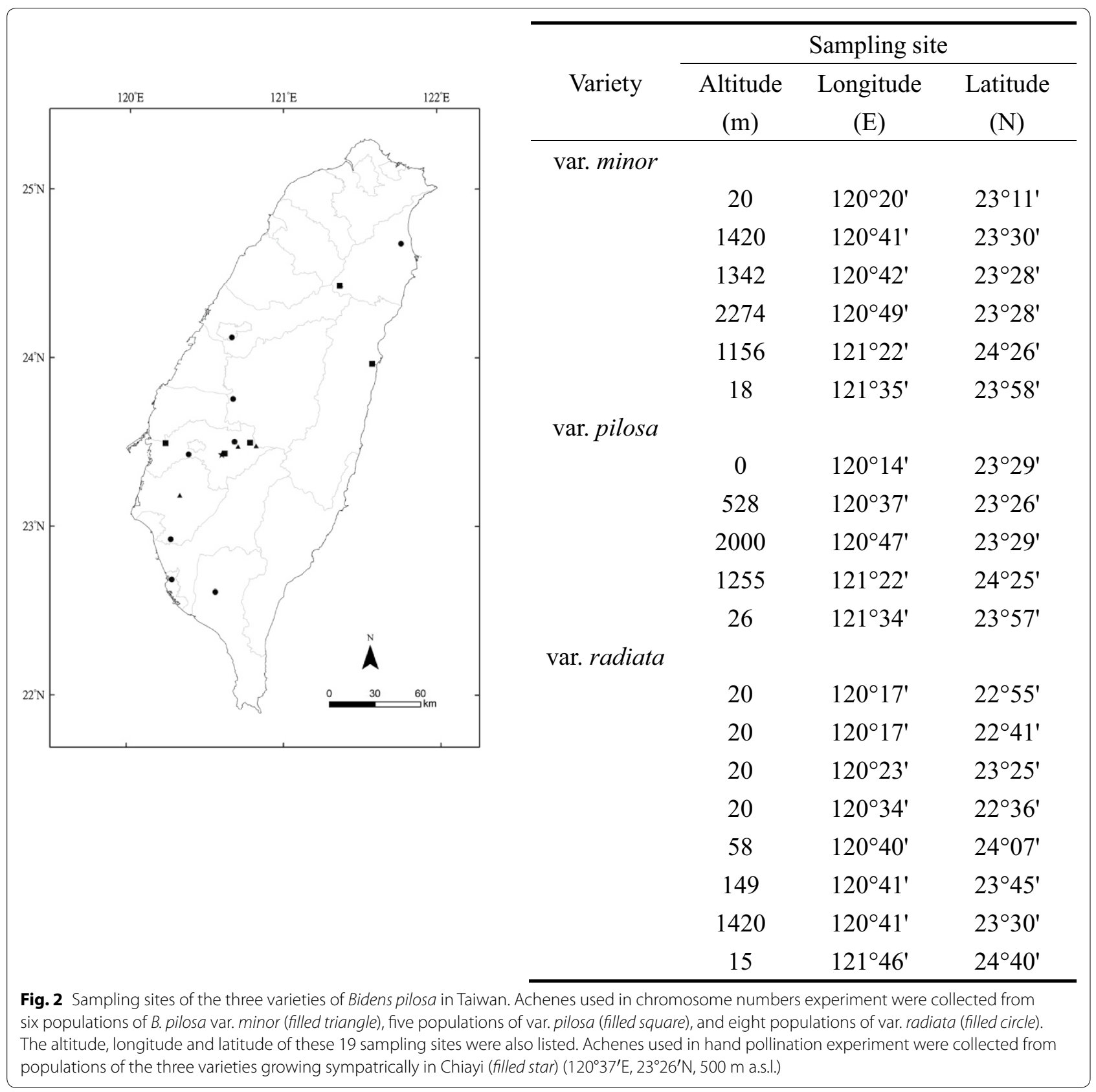


for $5 \mathrm{~h}$, fixed in Carnoy's solution (95\% EtOH: acetic acid $=3: 1, \mathrm{v} / \mathrm{v}$ ) for $24 \mathrm{~h}$ and then stored in $70 \% \mathrm{EtOH}$ at $-20{ }^{\circ} \mathrm{C}$. After washed with distilled water twice, rootlets were hydrolyzed in $1 \mathrm{~N} \mathrm{HCl}$ at $60{ }^{\circ} \mathrm{C}$ for $8 \mathrm{~min}$ and rinsed twice with distilled water. Following, materials were stained with leuco-basic fuchsin in the dark at room temperature for $2 \mathrm{~h}$ and treated with $1 \%$ pectinase at room temperature for $1 \mathrm{~h}$ to separate the connected cells. Roottips were spread on a slide and squashed in a drop of $45 \%$ acetic acid and then observed under a microscope (Grombone-Guaratini et al. 2006). Totally, 16 cells of var. minor, 7 cells of var. pilosa and 43 cells of var. radiata were counted.

\section{Hand-pollination experiment}

Achenes collected from a population in Chiayi $\left(120^{\circ} 37^{\prime} \mathrm{E}, 23^{\circ} 26^{\prime} \mathrm{N}, 500 \mathrm{~m}\right.$ a.s.l.) (Fig. 2, filled star), where the three varieties grew sympatrically, were planted in pots and placed in the experimental farm of National Taiwan University. After about 2 months, when these plants bloomed, their flowers were used in crossing trials. Because var. minor and var. pilosa are highly self-compatible and capable of self-pollinating (Huang and Kao 2014), it is difficult to prevent their pollen grains depositing on their own stigma. Therefore, these two varieties were assigned as pollen donors in crossing trials. In contrast, var. radiata being self-incompatible (Huang and Kao 2014) was assigned as pollen receivers in crosses. In addition, crosses between individuals of var. radiata from different populations were also conducted as control. Plants growing naturally in the experimental farm of National Taiwan University and those plants growing from the achenes collected from the Chiayi population were used as pollen donors and receivers, respectively.

Bidens pilosa produces inflorescence of capitulum. In its capitulum, the hermaphroditic disc florets opened in centripetal sequence, and the duration from the blooming of the first disc floret to the last disc floret is about 3-4 days (Huang et al. 2012). Therefore, hand pollination was conducted once a day consecutively for 3 or 4 days during the period of anthesis. To prevent the deposition of non-target pollen grains, the capitula assigned as pollen receivers were wrapped in fine nylon-mesh netting bags $(7 \times 9 \mathrm{~cm})$ as soon as their first disc florets opened until all disc florets on each capitulum withered. The capitula assigned as pollen donors were also wrapped into the netting bags to prevent contamination of pollen grains from other species.

At harvesting, the numbers of undeveloped ovules, immature and mature achenes were counted. Because there is only one ovule in each disc floret (Huang et al. 2012), the sum of mature achenes, immature achenes and undeveloped ovules represent the numbers of disc floret per capitulum.

\section{Results}

\section{Chromosome count}

The chromosomes of $B$. pilosa var. radiata, var. minor and var. pilosa shared similar size (ca. $2 \mu \mathrm{m}$ in length) and morphology (with centromeres in the central region of the chromosomes) (Fig. 1).

For each variety, plants collected from different populations had same chromosome numbers. However, different chromosome numbers were counted among the three varieties. Chromosome numbers of var. minor and var. pilosa were counted as $2 n=72$ (Fig. $1 \mathrm{~b}$, c, e and f), while those of var. radaita was $2 n=48$ (Fig. 1 h, i).

\section{Hand-pollination experiment}

In the crossing experiment, the capitulum of B. pilosa var. radiata assigned as pollen receivers had 21-57 disc florets in each capitulum (Table 1). In crossing trial, no viable achenes were produced when the stigmata of disc florets of var. radiata receiving either the pollen grains from var. minor or var. pilosa (Table 1) or pollen grains of their own. In contrast, 17-29 mature achenes were produced in one capitulum of var. radiata when their stigmata receiving pollen grains from other individuals of var. radiata.

\section{Discussion}

Different chromosome numbers were found between the invasive and non-invasive varieties of B. pilosa in Taiwan. Different ploid level is one of the most frequent reasons leading to difference in chromosome numbers in some genera of Asteraceae (Dematteis and Fernandez 2000; Keil et al. 1988; Solbrig et al. 1972). Therefore, the variation in chromosome numbers among the three varieties of B. pilosa might result from Polyploidy. The basic chromosome number for genus Bidens has been reported as

Table 1 Disc floret numbers and achene set in hand pollination experiment

\begin{tabular}{llcr}
\hline Pollen donor & \multicolumn{2}{l}{ Pollen receiver (var. radiata) } \\
\cline { 2 - 4 } & Disc floret & Mature achene & $\boldsymbol{n}$ \\
\hline var. minor & $48.7 \pm 3.4$ & $0 \pm 0$ & 3 \\
var. pilosa & $38.8 \pm 2.3$ & $0 \pm 0$ & 5 \\
var. radaita (self) & $31.8 \pm 4.5$ & $0 \pm 0$ & 4 \\
var. radiata (cross) & $42.3 \pm 3.3$ & $23.0 \pm 2.0$ & 6 \\
\hline
\end{tabular}

The disc floret number per capitulum, mature achene number per capitulum (mean $\pm \mathrm{SE}$ ), and the number of capitulum counted $(n)$ in crossing experiment by hand pollination in which Bidens pilosa var. radiata as a pollen receiver, receiving pollen from other varieties (var. minor or var. pilosa) or same individual of var. radiata (self), or other individuals of var. radiata (cross) 
$x=12$ (Ballard 1986). Accordingly, B. pilosa var. radiata is tetraploidy, while var. minor and var. pilosa are hexaploidy. A study on the breeding system of these three varieties found that var. radiata was self-incompatible, while var. minor and var. pilosa were self-compatible (Huang and Kao 2014). Thus, different ploid level might result in the different breeding systems among the three varieties. Similar results were also reported for $200 \mathrm{popu}-$ lations of B. pilosa species complex in Central America, where the tetraploid populations were self-incompatible while the hexaploid populations were self-compatible (Ballard 1986).

Recent studies showed that there is a link between Polyploidy and invasiveness (Beest et al. 2012; Goralski et al. 2014; Lowry and Lester 2006; Treier et al. 2009). A study compared 81 invasive species and their 2356 congeners found that invasive species are generally polyploidy (Pandit et al. 2011). In this study we found that the invasive var. radiata is polyploidy. However, the non-invasive varieties are also polyploidy and even have higher ploid level than the invasive one. In addition, B. bipinnata, the congener of the three varieties, which is not invasive in Taiwan is also a polyploidy $(2 n=72)$ (Peng and Hsu 1978). Furthermore, it is reported that in the native distribution range of $B$. pilosa species complex, var. minor and var. pilosa are more widespread and more dominant than var. radiata. Thus, Polyploidy alone cannot explain why var. radiata becomes more dominant than the other two varieties in Taiwan. There are some other traits, for example, the ability of vegetative reproduction (Hsu and Kao 2014) and its breeding system (Huang and Kao 2014), contributing to the invasiveness of var. radiata in Taiwan.

Results from hand pollination experiment and consistent chromosome numbers counted in populations of var. radiata indicated that var. radiata is unlikely to hybridize with var. minor or var. pilosa. Accordingly, highly variation in traits found in B. pilosa var. radiata is unlikely caused by hybridizing with other varieties. Instead, we have previously suggested that the highly heterogeneity in traits might result from the obligate xenogamous breeding system carried by var. radiata (Huang and Kao 2014). The characters of highly variation in many traits might play an important role contributing to the invasiveness of var. radiata in Taiwan.

Based on the morphological differences, Sherff (1937) classified B. pilosa into six varieties. Ballard (1986) investigated 200 populations of B. pilosa in central America and suggested that plants previously classified as var. pilosa and var. minor by Sherff's system still belonged to B. pilosa (hexaploid, $2 n=72$ ). But those being classified as var. radiata by Sherff should be treated as $B$. odorata (diploid, $2 n=24$ ) or $B$. alba (tetraploid, $2 n=48$ ), depending on their chromosome numbers. Accordingly, B. pilosa var. radiata in Taiwan might be treated as $B$. alba. Further studies on detailed morphological characters, geographic distribution and molecular phylogeny of the genus Bidens are suggested to confirm the systematics of the three varieties in Taiwan.

\section{Conclusions}

The invasive and non-invasive varieties of Bidens pilosa in Taiwan have different chromosome numbers and were different polyploid. The chromosome number of invasive var. radiata was $2 n=48$ (tetraploidy), while those of non-invasive var. minor and var. pilosa were $2 n=72$ (hexaploidy). The hand pollination experiment demonstrated that the invasive var. radiata is unlikely to hybridize with the non-invasive var. minor or var. pilosa. High variance of many traits found in invasive var. radiata might result from its self-incompatibility.

\section{Authors' contributions}

YLH designed the study, conducted the experiment, collected data and drafted the manuscript. WYK conceived the study, participated in its design and drafted the manuscript. Both authors read and approved the final manuscript.

\section{Author details}

${ }^{1}$ Institute of Ecology and Evolutionary Biology, National Taiwan University, 1 , Roosevelt Rd., Sec. 4, Taipei 106, Taiwan. ${ }^{2}$ Department of Life Science, National Taiwan University, 1, Roosevelt Rd., Sec. 4, Taipei 106, Taiwan.

\section{Acknowledgements}

We thank Cheng-En Li for plotting the figure of sampling sites. This study was partly supported by a grant from the National Science Council of Taiwan, R. O. C. (NSC 100-2621-B-002-004).

\section{Compliance with ethical guidelines}

\section{Competing interests}

The authors declare that they have no competing interests.

Received: 16 June 2015 Accepted: 9 September 2015

Published online: 18 September 2015

\section{References}

Ballard R (1986) Bidens pilosa complex (Asteraceae) in North and Central America. Am J Bot 73:1452-1465

Beest MTB, Le Roux JJ, Richardson DM, Brysting AK, Suda J, Kubešová M, Pyšek P (2012) The more the better? The role of polyploidy in facilitating plant invasions. Ann Bot 109:19-45

Dematteis M, Fernandez A (2000) Chromosome studies on nine South American species of Vernonia (Vernonieae, Asteraceae). Caryologia 53:55-61

Goralski G, Judasz A, Gacek P, Grabowska-Joachimiak A, Joachimiak AJ (2014) Polyploidy, alien species and invasiveness in Polish angiosperms. Plant Syst Evol 300:225-238

Grombone-Guaratini MT, Mansanares ME, Semir J, Solferini VN (2006) Chromosomal studies of three species of Bidens (L.) (Asteraceae). Caryologia 59:14-18

Hsu H-M, Kao W-Y (2014) Vegetative and reproductive growth of an invasive weed Bidens pilosa L.var. radiata and its noninvasive congener Bidens bipinnata in Taiwan. Taiwania 59:119-126

Huang Y-L, Kao W-Y (2014) Different breeding systems of three varieties of Bidens pilosa in Taiwan. Weed Res 54:162-168 
Huang Y-L, Chen S-J, Kao W-Y (2012) Floral biology of Bidens pilosa var. radiata, an invasive plant in Taiwan. Bot Stud 53:501-507

Keil DJ, Luckow MA, Pinkava DJ (1988) Chromosome studies in Asteraceae from the United States, Mexico, the West Indies, and South America. Am J Bot 75:652-668

Lowry E, Lester SE (2006) The biogeography of plant reproduction: potential determinants of species' range sizes. J Biogeogr 33:1975-1982

Pandit MK, Pocock MJO, Kunin WE (2011) Ploidy influences rarity and invasiveness in plants. J Ecol 99:1108-1115

Peng C-I, Hsu C-C (1978) Chromosome numbers in Taiwan Compositae. Bot Bull Acad Sin 19:53-66

Peng C-I, Chung K-F, Li H-L (1998) Compositae. In: C HT, Taiwan ECotFo (eds) Flora of Taiwan, vol 4. 2nd edn. Department of Botany, National Taiwan University, Taipei, Taiwan, pp 807-1101
Sherff EE (1937) The genus Bidens. Field Mus Nat Hist Bot Ser 11:412-461 Solbrig OT, Kyhos DW, Powell M, Raven PH (1972) Chromosome numbers in Compositae VIII: Heliantheae. Am J Bot 59:869-878

Treier UA, Broennimann O, Normand S, Guisan A, Schaffner U, Steinger T, Muller-Scharer $\mathrm{H}$ (2009) Shift in cytotype frequency and niche space in the invasive plant Centaurea maculosa. Ecology 90:1366-1377

Wu S-H, Hsieh C-F, Chaw S-M, Rejmanek M (2004) Plant invasions in Taiwan: insights from the flora of casual and naturalized alien species. Divers Distrib 10:349-362

Wu S-H, Yang TYA, Teng Y-C, Chang C-Y, Yang K-C, Hsieh C-F (2010) Insights of the latest naturalized flora of Taiwan: change in the past 8 years. Taiwania 55:139-159

\section{Submit your manuscript to a SpringerOpen ${ }^{\odot}$ journal and benefit from:}

- Convenient online submission

- Rigorous peer review

- Immediate publication on acceptance

- Open access: articles freely available online

- High visibility within the field

- Retaining the copyright to your article

Submit your next manuscript at $>$ springeropen.com 